\title{
1 The evolution of nasal immune systems in vertebrates
}

\section{Ali Sepahia, Irene Salinas ${ }^{a}$,*}

3 aCenter for Evolutionary and TheoreticalImmunology, Department of Biology,

4 University of New Mexico, Albuquerque, New Mexico, USA.

5 Corresponding author: Dr. Irene Salinas. Tel: +1 505 2770039. E-mail:

6 isalinas@unm.edu.

\section{Abstract}

9 The olfactory organs of vertebrates are not only extraordinary chemosensory 10 organs but also a powerful defense system against infection. Nasopharynx11 associated lymphoid tissue (NALT) has been traditionally considered as the first line

12 of defense against inhaled antigens in birds and mammals. Novel work in early 13 vertebrates such as teleost fish has expanded our view of nasal immune systems, 14 now recognized to fight both water-borne and air-borne pathogens reaching the 15 olfactory epithelium. Like other mucosa-associated lymphoid tissues (MALT), NALT 16 of birds and mammals is composed of organized lymphoid tissue (O-NALT) (i.e 17 tonsils) as well as a diffuse network of immune cells, known as diffuse NALT (D18 NALT). In teleosts, only D-NALT is present and shares most of the canonical features 19 of other teleost MALT. This review focuses on the evolution of NALT in vertebrates 20 with an emphasis on the most recent findings in teleosts and lungfish. Whereas 21 teleost are currently the most ancient group where NALT has been found, lungfish 22 appear to be the earliest group to have evolved primitive O-NALT structures.

\section{Keywords}

25 Evolution; Nasal immunity; NALT, mucosal immunity; vertebrates; teleost fish 


\section{1. Historical aspects}

28 Tonsillectomy or the surgical removal of tonsils is a very ancient practice. 29 Approximately 2000 years ago,Aulus Cornelius Celsus, a Roman writer and 30 physician, described tonsil surgery by using his fingers to remove tonsils(Koempel 31 et al., 2006; Younis and Lazar, 2002).Today, 530,000 children under the age of 15

32 have theirs tonsils or adenoids removed in the US every year and it is still one of the

33 most common surgical procedures in children in this country (Cullen et al., 2009;

34 Roland et al., 2011).

35 The first attempt tonasally vaccinate humans against smallpox was reported in the

36 Golden Mirror of Medicine, Chinese medical text in 1742. Nasal vaccination was

37 done by using powdered scabs that were blown to the nose or filling the nose with a 38 vesicle smeared cotton(Plotkin, 2014).Thus, tonsillectomy and nasal vaccination 39 precede our understanding of nasal immune systems.

40 Anatomically, the human Waldeyer's ring was first described in 1884 by von 41 Waldeyer-Hartz as a ring of lymphoid tissue in the pharyngeal wall(Cocquyt et al., 42 2005; Perry and Whyte, 1998).Nasopharynx-associated lymphoid tissue (NALT)

43 was first described as a paired of lymphoid cells accumulations in the nasal passage 44 of rat in 1947(Kelemen, 1947)whilst the mouseNALT was first describedfew 45 decades later(Belal et al., 1977).In the subsequent years, the NALT of other 46 mammals such as monkeys(Harkema et al., 1987; Loo and Chin, 1974) and 47 horses(Mair et al., 1987; Mair et al., 1988)were described.However these studies did 48 not include functional aspects of the nasal immune system(Kuper et al., 1992).

49 One of the major breakthroughs in nasal immunity field took place in the early 2000, 50 when the first nasal vaccinefor use in humans against influenza virus was licensed 51 in the USA(FluMist)(Chen et al., 2006).To date, this vaccine remains the only nasal

52 vaccine licensed for human use. The effectiveness and availability of this vaccine has

53 helped the NALT community to expand basic scientific knowledge on nasal immune 54 responses. Intranasal vaccination offers a number of advantages over other 55 vaccination routes(Neutra and Kozlowski, 2006). Apart from the fact that is needle 
56 free and requires small amounts of antigen, intranasal delivery has been shown to

57 stimulate not only local nasal immunity but also systemic immune responses as well

58 as mucosal immune responses in distant mucosal sites(Fukuyama et al., 2012;

59 Lycke, 2012; Neutra and Kozlowski, 2006; Pabst, 2015).

\section{2. Anatomy of NALT}

61 In endotherms, mucosa-associated lymphoid tissues (MALT) comprise a network of 62 secondary lymphoid tissues that contain both well-organized lymphoid structures 63 (organized MALT, O-MALT) and scattered or disseminated lymphoid cells (diffuse 64 MALT, D-MALT) (Brandtzaeg and Pabst, 2004). Examples of O-MALT include the 65 Peyer's patches in the gut or the tonsils in the nasopharyngeal cavity. Generally 66 speaking we know very little about NALT (both organized and diffuse) compared to 67 the gut-associated lymphoid tissue (GALT). Furthermore,most mammalian 68 studiesfocus on organized NALT(O-NALT), whereas diffuse NALT (D-NALT) has 69 received very little attention. It is worth noting that the term "non-NALT" can also 70 be found in the literatureinstead of D-NALT (Asanuma et al., 1997; Lee et al., 2015;

71 Tamura et al., 1998). Additionally, "nasal passage (NP) leucocytes" is another term 72 that can be found in the mammalian literature referring to D-NALT (Hiroi et al., 73 1998; Rodríguez-Monroy et al., 2007; Shikina et al., 2004). Despite the fact that the

74 Society for Mucosal Immunology does not recommend the use of O-MALT and D75 MALT (Brandtzaeg et al., 2008),numerous mammalian immunologists continue to 76 use this terminology. Moreover, from the evolutionary immunologist point of view, 77 O-NALT and D-NALT are useful terms considering that early vertebrates lack 0-

78 NALT (Figure 1). In the next part of this review, we will summarize the basic 79 anatomical aspects of NALT in different vertebrate groups.

\section{2.1. Rodents and humans}

81 The anatomy and structure of O-NALT have been widely studied in rodents 82 (Mestecky et al., 2005). Murine NALT is composed of a pair of organized mucosal 83 organs located on the roof of the soft palate at the entrance to the nasopharyngeal 84 duct (Liang et al., 2001). NALT in mouse is considered by some to be analogous to 
85 the Waldeyer's ring in human which consists of the adenoids and tonsils (Kuper et 86 al., 1992). Thus, in both mice and humans, O-NALT is strategically placed in the 87 upper airways to combat air-borne antigens. Perhaps, this anatomical observation

88 historically hindered the investigation of NALT in non-terrestrial vertebrates.

89 It is important to highlight that O-NALT of rodents and humans appears to be 90 significantly different anatomically speaking. In rodents, NALT is located in a single

91 localization bilateral at the entrance of the nasopharyngeal ductwhereas in human 92 studies conducted in children, O-NALT was mostly found in the middle concha and it 93 consisted of disseminated lymphoid, subepithelial follicles (Debertin et al., 2003).

94 The results from this study indicated that children have O-NALT structures in 95 addition to a Waldeyer's ring (Debertin et al., 2003). Additionally, these differences 96 underscore the fact that mice may not be the best models for human nasal immunity 97 studies.

98 Similar to the Peyer's patches in the gut, O-NALT structures are located underlying 99 specialized portions of the epithelium known as follicle-associated epithelium 100 (FAE). Additionally, high endothelial venules (HEVs) control lymphocyte trafficking 101 into O-NALT (Kiyono and Fukuyama, 2004). O-NALT structures also have distinct B102 lymphocyte and T-cell zones (Bailey et al., 2005; Brandtzaeg and Pabst, 103 2004).Germinal center formation occurs in O-NALT in response to infection or 104 antigenic stimulation(Zuercher et al., 2002).

105 As mentioned earlier, both mice and humans also possessdiffuse lymphoid cells 106 situated on the mucosa of the nasal passages called (D-NALT)(Liang et al., 2001).D107 NALT includes myeloid cells and lymphoid cells(both B and T cells). The similarities 108 and differences between mammalian O-NALT and D-NALT are summarized in Table 1091.

$110 \quad$ 2.2. Other mammals 
111 In this section, we are going to focus on reports pertaining four groups of mammals:

112 cattle, sheep, canines and rabbits. The studies in these species have been motivated

113 by the importance of nasal vaccination in veterinary medicine.

114 In cattle, the tonsil (O-NALT) was first described in 1992(Schuh and Oliphant,

115 1992). Cattle tonsils are located at the entry of the pharynx and are equivalent to the

116 Waldeyer's ring in humans(Rebelatto et al., 2000).During development, adenoid can

117 be detected at 95 days of gestation. Moreover, ciliated, microvillus cells and a loose

118 accumulation of mononuclear cells in lamina propia is visible at 120 to 150 days of

119 gestation. Small lymphoid follicles form at 4 to 5 months of gestation following by

120 the appearance of goblet cells after 5 months of gestation(Schuh and Oliphant, 121 1992). Tonsils are well developed at birth in cattle. However, germinal center 122 formation and increase in MHC class II expression only occur in the late natal and 123 early post-natal period(Schuh and Oliphant, 1992).Moreover, cattle infected with 124 foot-and-mouth disease virus (FMDV) showed increased expression of TLR-4 in 125 NALT, indicating the importance of type I IFN responses in NALT against FMDV 126 (Zhang et al., 2006).

127 Sheep 0-NALTstructures, similar to horse O-NALT, are clustered posterior to the 128 opening of the Eustachian tube (Mair et al., 1988; Stanley et al., 2001). Thus, ovine 129 NALT is highly organized and consists of discrete B and T cells areas similar to those 130 found of humans and rodents. Furthermore, it has been shown that sheep NALT is 131 covered by ciliated and non-ciliated cells which play an important role in antigen 132 uptaking and processing (Stanley et al., 2001).

133 Peeters et al. (2005) reported the absence of typical O-NALT structures in the nasal 134 mucosa of dogs without respiratory disease(Peeters et al., 2005).Waldeyer's ring in 135 the dog consists of the lingual tonsil, the palatine tonsils, the soft palate tonsil and 136 the pharyngeal tonsil or adenoid (Billen et al., 2006). The nasopharyngeal mucosa in 137 dogs appears uniform and the nasopharyngeal tonsil is not obvious (Billen et al., 138 2006).The latter might be due to the fact that dogs breathe through both the nose 139 and the mouth; therefore, exposure of the canine nasal and nasopharyngeal mucosa 
140 to inhaled antigens is decreased. This may explain why the pharyngeal tonsil is less

141 developed in dogs than horses, cattle, sheep and pigs(Billen et al., 2006).

142 Casteleyn et al (2010) histologically examined the presence of NALT in rabbits by 143 sectioning the nasal cavity. Rabbits appear to have well organized NALT in their

144 nasal cavities including clustered I and II lymphoid follicles separated by 145 interfollicular regions as well as isolated lymphoid follicles. Interestingly, in the 146 middle third of rabbit nasal cavity,NALT occupied the largest space. The rabbit and

147 human nasal cavities occupy a similar volume considering their respective body 148 masses. However, in comparison with rodents, O-NALT in the rabbit is more 149 abundant. Therefore the similarities between human and rabbit nasal cavities 150 suggest that the rabbit is a better model for intranasal vaccine development than 151 rodents are(Casteleyn et al., 2010). Additionally, rabbits have a D-NALT 152 characterized by intraepithelial and lamina propria lymphocytes (Casteleyn et al., 153 2010).

\section{2.3. Birds}

155 Most of our knowledge on avian NALT comes from studies in chicken and duck. The 156 nasal cavity in chickens is cone-shaped and separated into the right and left sides by 157 a cartilaginiformnasal septum. The majority of the nasal cavity is occupied by the 158 turbinates which play a major role in preventing the entry of dust and 159 microbes(Kang et al., 2013). Lymphoid nodules are the main O-NALT structure in 160 chickens. Nodules are made of B cells with developed germinal centers, surrounded 161 by a coat of CD4+T cells.

162 Chicken D-NALT, on the other hand, consists mostly of CD8 ${ }^{+} \mathrm{T}$ cellsthat can be found 163 in the epithelium and in the lamina propria ofthe nasal mucosa(Kang et al., 2013;

164 Ohshima and Hiramatsu, 2000). Additionally, scattered lymphoid cells are found in 165 the paranasal organs of chickens (nasolacrimal ducts, lateral nasal glands and their 166 ducts) (Bang and Bang, 1968; Kang et al., 2013). 
167 NALT appears to be an important inductive site for the chicken's mucosal immune 168 system, however, the low absorption rates of antigen by the nasal mucosa may limit 169 induction of effective nasal immune responses(Kang et al., 2013).

170 The nasal cavity in duck is cone-shaped and separated into right and left sides by a 171 nasal septum(Kang et al., 2014).At the caudal regions of the nasal cavity there are 172 two pairs of symmetrical lymphoid aggregates; one pair located on the dorsal side of 173 the choanal cleft and the other pair on both sides of nasal septum (Kang et al, 2014). 174 The FAE found in duck O-NALT, unlike that of rodents, contains almost no goblet 175 cells.The use of liquid vaccines for ducklings and dry powder vaccine sprays for 176 adult duckshas been recommended because liquid vaccinesare unlikely to reach the 177 NALT located on the nasal septum in adult ducks(Kang et al., 2014).

178 Like the chicken, ducks have diffuse lymphoid tissue and intraepithelial 179 lymphocytes located within their nasal walls and turbinalia randomly (Kang et al., 180 2014).

181 2.4. Reptiles and amphibians

182 Unfortunately, NALT has been studied neither in reptiles nor in amphibians. This is 183 despite the fact that chelonids are affected by upper respiratory tract disease 184 (URTD) caused by Mycoplasma agassizii(Brown et al., 1999). The infection results in 185 nasal discharge, nasal wheeze, conjunctivitis and inflammation of the oral mucosa. 186 The contribution of NALT responses in M. agassizii infected chelonids should be 187 investigated

188 Amphibians are known to have both diffuse and organized GALT and 189 NALT(Goldstine et al., 1975). Tonsil-like structures were found in the lingual and 190 sublingual regions of anuran amphibians(Myers, 1928). We further identified 191 lymphoid aggregates associated with the olfactory epithelium of Lithobates $s p$. 192 Tadpoles(Tacchi et al., 2015). Based on histological examination, these were present 193 immediately underneath the olfactory epithelium but did not appear as organized as 194 those found in lungfish. Contrary to birds and mammals, amphibian O-MALT is 
195 characterized by lymphoid nodules or aggregates that lack B and T cell zones or GC

196 formation (Goldstine et al., 1975).

197 2.5. Sarcopterygian fishes

198 Sarcopterygian fish such as lungfish are the closest living sister species to all 199 tetrapods(Zardoya and Meyer, 1996). Moreover, lungfish represent the transition

200 from aquatic to terrestrial environments during vertebrate evolution and are 201 exposed to both air-borne and water-borne antigens. We recently discovered that 202 African lungfish (Protopterus sp.) may be the most ancient vertebrate where 0203 MALT, including O-NALT, is found (Figure 1). O-NALT structures in lungfish are 204 FAE-associated or embedded in the mucosa of the upper and lower jaw (Figure 2).

205 They are mostly composed of lymphocytes both B and T cells and do not display GC 206 formation(Tacchi et al., 2015).In response to bacterial infection, lungfish 0-NALT 207 architecture and cellular composition changes, with an increase in the percentage of

$208 \mathrm{~T}$ and B cells compared to uninfected controls. Although not covered in the same 209 study, we anticipate the presence of D-NALT in lungfish, but their characteristics 210 need to be investigated. The discovery of these primordial forms of O-NALT in 211 lungfish along with the ability to infect these animals intranasally in the laboratory 212 makes this species an interesting system for investigating the structure, 213 organogenesis and function of O-MALT in ectotherms.

\section{$214 \quad$ 2.6. Teleosts}

215 Until recently, three MALT have been characterized in teleost fish: gut-associated 216 lymphoid tissue (GALT), skin-associated lymphoid tissue (SALT) and gill-associated 217 lymphoid tissue(Salinas et al., 2011). However, we have discovered that NALT is 218 likely conserved in all jawed vertebrates as it was found in teleost fish. Teleost NALT 219 resembles other teleost MALT in many regards such as the presence of diffuse 220 lymphoid cells with no organized structures present, a predominant constitutive 221 presence of $\operatorname{IgT}^{+}$B cells and secreted IgT compared to systemic lymphoid tissues 222 and the presence of an associated microbiota coated by mucosal immunoglobulins 
223 (Tacchi et al., 2014). This discovery broke the previous paradigm of nasal immune

224 systems being a first line of defense against inhaled antigens.

225 Histological examination of the NALT of four different families of teleost fishshowed 226 that teleost NALT harborsdiffuse lymphoid cells but lacksO-NALT (Tacchi et al., 227 2014).One of the key features of teleost MALT is the preponderant presence of IgT ${ }^{+}$ 228 B cells and secreted IgT into mucosal secretions(Zhang et al., 2010). Trout D-NALT 229 contains abundant B cells, $48.5 \%$ are $\mathrm{IgM}^{+} \mathrm{B}$ cells and $51.5 \% \%$ are $\mathrm{IgT}^{+} \mathrm{B}$ cells, 230 following the canonical B cell composition of other trout MALT. Similarly, the ratio 231 of secreted IgT and secreted IgM in nasal mucus is much higher than that in plasma, 232 again highlighting that trout NALT shares the main features of other MALT in 233 teleosts. In gut and skin, previous studies have shown that specific IgT but not IgM 234 responses occur in the local mucosal environment in response to parasitic infections 235 in rainbow trout(Xu et al., 2013; Zhang et al., 2010). Although we detected high 236 levels of IgT in the nasal secretion of trout in the absence of antigenic stimulation, 237 specific IgT responses in the olfactory organ of teleosts in response to infection or 238 vaccination are yet to be investigated.We have demonstrated striking protection 239 levels conferred by nasal vaccines against viral and bacterial pathogens of fish in 240 rainbow trout however, the mechanisms underlying the observed protection are not 241 well understood and may include both humoral and cellular immunity (LaPatra et 242 al., 2015; Tacchi et al., 2014).

243 Using a live attenuated infectious hematopoietic necrosis virus (IHNV) model of 244 nasal vaccination, we were able to show that trout NALT mounts strong innate and 245 adaptive immune responses over the course of a 28 day experiment. Whereas the 246 expression of innate immune genes peaked at day 4 post vaccination, expression of 247 adaptive immune genes peaked at day 14. Additionally, nasal vaccination resulted in 248 stimulation of immune genes not only in NALT but also in the head-kidney (Tacchi 249 et al, 2014).

250 Altogether, our results clearly reveal that early bony vertebrates evolved olfactory 251 organs with strong defense functions that serve as a primary mucosal immune 
252 barrieragainst pathogens. Moreover, the discovery of teleost NALT and detection of

253 nasal immune responses in trout in response to vaccination underscores the fact 254 that strong nasal immune responses in vertebrates can take place in the absence of

255 O-NALT. Currently, surgical ablation of O-NALT in mice is used as a tool to evaluate

256 the specific contribution of O-NALT to mammalian nasal immune responses. This

257 method is complex and may result in incomplete removal of all O-NALT cells. Thus,

258 we propose that teleost NALT is an excellent model for the study of D-NALT and can

259 provide a unique tool to understand, for instance, how tonsillectomized humans

260 respond to nasal vaccines.

\section{3. Evolution of NALT-specific molecules in vertebrates}

262 The mucosal immune system has evolved complex suites of immune molecules as 263 well as cell adhesion and trafficking molecules that separate it from the systemic 264 immune system. For instance, trafficking of lymphocytes to NALT in mice is 265 governed by the PNad-L-selectin pair (Csencsits et al., 1999; Fukuyama et al., 2002), 266 whereas the $\alpha 4 \beta 7$-MAdCAM-1 pair governs trafficking of lymphocytes to the gut 267 (Berlin et al., 1995).

268 The development of lymphoid tissues mainly relies on the lymphotoxin-driven 269 expression of homeostatic chemokines such as CXCL13 (Ansel et al., 2000; Randall 270 and Mebius, 2014). CXCL13 also plays an important role in maintaining the 271 lymphoid architecture of NALT such as formation of germinal centers (Rangel272 Moreno et al., 2005). In NALT, however, additional chemokines like CCL20 and CCL9 273 which are important in dendritic cell and B cell migration are required for 274 development (Zhao et al., 2003). Impaired expression of CCL19/CCL21 results in 275 defects in influenza-specific CD8 T cells responses in NALT of lymphotoxin- $\alpha$ 276 deficient $\left(\mathrm{Lt}^{-}{ }^{-}\right.$) ) and plt/plt mice (Rangel-Moreno et al., 2005).

277 We know very little about the role of chemokines in the nasal immune system of 278 vertebrates other than mice and humans. In trout, we found CCL19 expression was 279 upregulated around 50-fold at 4 days post vaccination with live attenuated IHNV 
suggesting a conserved role of this chemokine in vertebrate nasal immunity (Tacchi

281 et al., 2014).

282 With respect to O-MALT evolution, it has been proposed that organization of 283 lymphocytes in structures such as lymph nodes or O-MALT is an endotherm284 restricted innovation.Lymphocyte organization requires the presence of certain 285 molecular signals that create the adequate microenvironment for $\mathrm{B}$ and $\mathrm{T}$ cells. Most 286 of the molecules that play a role in lymphocyte organization belong to the tumor 287 necrosis factor superfamily (TNFSF)(Tacchi et al., 2015). In this respect, we recently 288 provided new insights into the evolution of TNFSF and showed that it greatly 289 diversified in African lungfish. Among TNFSF members, lymphotoxins are of 290 particular relevance due to their function in the organization of lymphoid tissues. 291 Interestingly, where lymphotoxin beta receptor (LTBR) is found from teleosts to 292 humans, lymphotoxin alpha (LTA) and beta (LTB) are absent in teleosts but found in 293 lungfish. In other words, TNFSF members known to be essential in lymphocyte 294 organization in mammals first appeared in lungfish and are absent from teleost 295 genomes. Moreover, a number of these TNFSF members were found to be expressed 296 in African lungfish O-NALT(Tacchi et al., 2015).

297 ID2 is a transcription factor known to be essential for O-NALT formation. ID2 is 298 involved in the induction of $\mathrm{CD}^{-}{ }^{-C D} 4{ }^{+} \mathrm{CD} 45^{+}$cells (Yokota et al., 1999) and ID2 299 deficient mice could not develop NALT after birth (Fukuyama et al., 2002; Yokota et 300 al., 1999). We found ID2 expressed both in trout and lungfish NALT and its 301 expression was significantly modulated upon nasal vaccination with a viral vaccine 302 or nasal bacterial infection, respectively (Tacchi et al., 2014).Important molecules in 303 the formation of NALT in mice are summarized in Table 2.

\section{4. Nasal microbiota and immunity in vertebrates}

305 Every animal mucosal surface is colonized by millions of microorganisms forming a 306 very ancient and successful symbiosis between prokaryotes and metazoans. The 307 microbiota controls the immunological development of the host by different 308 mechanisms such as inhibition of pathogen colonization on mucosal surfaces and 
309 stimulation of the host immune system(Buffie and Pamer, 2013; Kiyono and 310 Fukuyama, 2004; Randall and Mebius, 2014). Although the number of studies 311 revealing the importance of the microbiota in GALT development and function is 312 vast, information regarding its effects on NALT is limited.

313 The nasal microbiome of human was sequenced and characterized in 2010 and 314 further studies continue to determine its role in health and disease(Dewhirst et al., 315 2010).In humans, over $96 \%$ of the nasal bacterial microbiome belongs to three 316 phyla: Actinobacteria, Firmicutes and Proteobacteria(Yan et al., 2013). In other 317 mammalian species such as pigs, the nasal microbiome is Proteobacteria, Firmicutes 318 and Spirochaetes(Weese et al., 2014). Nasal-associated microbiota are also present 319 in aquatic vertebrates as evidenced by our studies in rainbow trout (Tacchi et al, 320 2014). The bacterial community associated with the trout olfactory organ is very 321 diverse. 16s rDNA pyrosequencing revealed the presence of 18 total bacterial phyla, 322 the highest number of phyla present among all body sites. The bacterial community 323 was dominated by Proteobacteria, Actinobacteria, Bacteriodetes and Firmicutes 324 with the class Betaproteobacteria accounting for 15.1 - $53.6 \%$ of all 325 sequences(Lowrey et al., 2015).Thus, although limited pyrosequencing data is 326 available, it appears that Proteobacteria and Firmicutes may be the most dominant 327 and conserved taxa among nasal microbiomes in vertebrates, further studies will 328 confirm or reject this hypothesis.The trout nasal microbiome composition is distinct

329 from that of any other trout mucosal surface but most closely resembles that of the 330 skin.

331 The presence of unique bacterial communities in association with each mucosal 332 anatomical site suggests a tight cross-talk between the microbiota and MALT in 333 vertebrates. One of the ways by which the microbiota and the host immune system 334 interact is by means of secretory immunoglobulins that help anchor 335 microorganisms to the mucus layer, while tagging them in a process known as 336 immune exclusion.As an example, trout nasal-associated bacteria, similar to gut and 337 skin bacteria, are coated by secretory immunoglobulins. Particularly, in trout skin 338 and gut mucus, the immunoglobulin isotype $\operatorname{IgT}$ has specialized in the role of 
339 bacteria coating(Xu et al., 2013; Zhang et al., 2010) with IgM coating significantly 340 lower numbers of bacteria. In nasal mucus, however, an equal proportion of bacteria 341 were coated with IgM or IgT and the proportion of bacteria coated with both

342 isotypes was higher than that found in the gut and skin (Tacchi et al., 2014).

343 From mammalian studies it appears clear that the microbiota plays a key role in the 344 form and function of NALT. For instance, the microbiota was shown to modulate 345 local nasal T cell responses against Mycoplasma pulmonis infection(Henriksson et al., 346 2004). On the other hand, the composition of the nasal microbiome of humans is a 347 determinant of Staphylococcus aureus colonization and carriage(Frank et al., 2010;

348 Yan et al., 2013)and, in mice, it regulates the immune responses against respiratory 349 influenza A virus infection(Ichinohe et al., 2011).Additionally, it has been shown 350 that the number of M cells in NALT of specific pathogen free rats is lower compared 351 to normally reared rats (Jeong et al., 2000) and the numbers of T and B cells in NALT 352 are 2-3 times greater after an experimental infection (Asanuma et al., 1997).NALT, 353 like most of the lymphoid organs, can develop in germ free mice. NALT development

354 CXCL5-deficient mice in sterile conditions takes about 20 weeks, however by 355 repeated intranasal application of heat inactivated $P$. acnes suspension, NALT can be

356 induced after 8 weeks (Krege et al., 2009).In the future, the specific roles of the nasal 357 microbiota on the development and function of vertebrate NALT should be further 358 elucidated.

\section{How old is NALT?}

361 Our current view of nasal immunity is limited and mostly restrictedto mammalian 362 studies. We provided the first evidence supporting the idea that nasal immunity is 363 an ancient arm of the mucosal immune system of vertebrates. Furthermore, our 364 studies underscore that D-NALT, as anticipated, precedes the appearance of O-NALT 365 during evolution (Figure 1). Currently, we can state that D-NALT is at least $380 \mathrm{MY}$ 366 old, although we anticipate the cartilaginous fish and even agnathans may be 367 equipped with an equivalent immune system associated with their olfactory organs. 
368 How old is O-NALT is a separate question. We have provided evidence of primitive 369 O-NALT structures in the African lungfish, indicating that the ancestor to all 370 tetrapods first acquired this immunological innovation(Tacchi et al., 2015). Further

371 studies should address the immune function of primitive O-NALT in ectotherms.

\section{6. Concluding remarks}

373 Olfaction is one of the most ancient and conserved sensory systems in vertebrates. It 374 seems that the successful structure and function of olfactory organs evolved to not 375 only provide the exquisite detection of odorants but also to ensure that pathogens 376 do not gain entry into hosts via this route. We hope that our pioneer studies in NALT 377 evolution motivate more studies in non-mammalian models that complete our 378 understanding of nasal immune systems and their evolution. Future studies in 379 teleosts may address whether specific IgT is the main immunoglobulin isotype in 380 nasal adaptive immune responses and whether nasal vaccination can lead to 381 protection in other distant MALT. Lungfish studies, on the other hand, should try to 382 address what evolutionary advantages lymphocyte organization confers at mucosal 383 sites in the absence of germinal center formation.

\section{Acknowledgments}

385 This work was funded by awards NSF IOS \# 1456940 and USDA AFRI \# 2DN70386 2RDN7 to IS. Authors thank Victoria Hansen for the artwork.

\section{$387 \quad$ References}

388 Ache, B. W.,Young, J. M., 2005. Olfaction: diverse species, conserved principles. 389 Neuron 48, 417-430.

Adachi, S., Yoshida, H., Honda, K., Maki, K., Saijo, K., Ikuta, K., Saito, T.,Nishikawa, S.-I., 1998. Essential role of IL-7 receptor alpha in the formation of Peyer's patch anlage. Int. Immunol. 10, 1-6.

Ansel, K. M., Ngo, V. N., Hyman, P. L., Luther, S. A., Förster, R., Sedgwick, J. D., Browning, J. L., Lipp, M.,Cyster, J. G., 2000. A chemokine-driven positive feedback loop organizes lymphoid follicles. Nature 406, 309-314.

Asanuma, H., Hodson Thompson, A., Iwasaki, T., Sato, Y., Inaba, Y., Aizawa, C., Kurata, T.,Tamura, S.-i., 1997. Isolation and characterization of mouse nasalassociated lymphoid tissue. J. Immunol. Methods 202, 123-131. 
Bailey, M., Haverson, K., Inman, C., Harris, C., Jones, P., Corfield, G., Miller, B.,Stokes, C., 2005. The development of the mucosal immune system pre-and postweaning: balancing regulatory and effector function. Proc. Nutr. Soc. 64, 451457.

Bang, B. G.,Bang, F., 1968. Localized lymphoid tissues and plasma cells in paraocular and paranasal organ systems in chickens. Am. J. Pathol. 53, 735.

Belal, A., El-Gohery, Y.,Talaat, M., 1977. Nasal and paranasal pathology in experimental bilharziasis. J. Laryngol. Otol. 91, 391-400.

Berlin, C., Bargatze, R., Campbell, J., Von Andrian, U., Szabo, M., Hasslen, S., Nelson, R., Berg, E., Erlandsen, S.,Butcher, E., 1995. $\alpha 4$ integrins mediate lymphocyte attachment and rolling under physiologic flow. Cell 80, 413-422.

Billen, F., Peeters, D., Dehard, S., Day, M.,Clercx, C., 2006. Distribution of leucocyte subsets in the canine pharyngeal tonsil. J. Comp. Pathol. 135, 63-73.

Brandtzaeg, P., Kiyono, H., Pabst, R.,Russell, M., 2008. Terminology: nomenclature of mucosa-associated lymphoid tissue. Mucosal Immunol. 1, 31-37.

Brandtzaeg, P.,Pabst, R., 2004. Let's go mucosal: communication on slippery ground. Trends Immunol. 25, 570-577.

Brown, M., McLaughlin, G., Klein, P., Crenshaw, B., Schumacher, I., Brown, D.,Jacobson, E., 1999. Upper respiratory tract disease in the gopher tortoise is caused by Mycoplasma agassizii. J. Clin. Microbiol. 37, 2262-2269.

Buffie, C. G.,Pamer, E. G., 2013. Microbiota-mediated colonization resistance against intestinal pathogens. Nat. Rev. Immunol. 13, 790-801.

Casteleyn, C., Broos, A., Simoens, P.,Van Den Broeck, W., 2010. NALT (nasal cavityassociated lymphoid tissue) in the rabbit. Vet. Immunol. Immunopathol. 133, 212-218.

Chen, Z., Aspelund, A., Kemble, G.,Jin, H., 2006. Genetic mapping of the cold-adapted phenotype of B/Ann Arbor/1/66, the master donor virus for live attenuated influenza vaccines (FluMist $($ ). Virology 345, 416-423.

Cocquyt, G., Baten, T., Simoens, P.,Van Den Broeck, W., 2005. Anatomical localisation and histology of the ovine tonsils. Vet. Immunol. Immunopathol. 107, 79-86.

Csencsits, K. L., Jutila, M. A.,Pascual, D. W., 1999. Nasal-associated lymphoid tissue: phenotypic and functional evidence for the primary role of peripheral node addressin in naive lymphocyte adhesion to high endothelial venules in a mucosal site. J. Immunol. 163, 1382-1389.

Cullen, K. A., Hall, M. J., Golosinskiy, A.,Statistics, N. C. f. H., 2009. Ambulatory surgery in the United States, 2006. US Department of Health and Human Services, Centers for Disease Control and Prevention, National Center for Health Statistics, Maryland.

De Togni, P., Goellner, J., Ruddle, N. H., Streeter, P. R., Fick, A., Mariathasan, S., Smith, S. C., Carlson, R., Shornick, L. P.,Strauss-Schoenberger, J., 1994. Abnormal development of peripheral lymphoid organs in mice deficient in lymphotoxin. Science 264, 703-707.

Debertin, A., Tschernig, T., Tönjes, H., Kleemann, W., Tröger, H.,Pabst, R., 2003. Nasal-associated lymphoid tissue (NALT): frequency and localization in young children. Clin. Exp. Immunol. 134, 503-507. 
Dewhirst, F. E., Chen, T., Izard, J., Paster, B. J., Tanner, A. C., Yu, W.-H., Lakshmanan, A.,Wade, W. G., 2010. The human oral microbiome. J. Bacteriol. 192, 50025017.

Frank, D. N., Feazel, L. M., Bessesen, M. T., Price, C. S., Janoff, E. N.,Pace, N. R., 2010. The human nasal microbiota and Staphylococcus aureus carriage. PLoS ONE. 5, e10598.

Fukuyama, S., Hiroi, T., Yokota, Y., Rennert, P. D., Yanagita, M., Kinoshita, N., Terawaki, S., Shikina, T., Yamamoto, M.,Kurono, Y., 2002. Initiation of NALT organogenesis is independent of the IL-7R, LT $\beta \mathrm{R}$, and NIK signaling pathways but requires the Id 2 gene and CD3- CD4+ CD45+ cells. Immunity $17,31-40$.

Fukuyama, S., Nagatake, T., Kim, D.-Y., Takamura, K., Park, E. J., Kaisho, T., Tanaka, N., Kurono, Y.,Kiyono, H., 2006. Cutting edge: uniqueness of lymphoid chemokine requirement for the initiation and maturation of nasopharynxassociated lymphoid tissue organogenesis. J. Immunol. 177, 4276-4280.

Fukuyama, Y., Tokuhara, D., Kataoka, K., Gilbert, R. S., McGhee, J. R., Yuki, Y., Kiyono, H.,Fujihashi, K., 2012. Novel vaccine development strategies for inducing mucosal immunity. Expert Rev. Vaccines 11, 367-379.

Goldstine, S. N., Manickavel, V.,Cohen, N., 1975. Phylogeny of gut-associated lymphoid tissue. Am. Zool. 15, 107-118.

Harkema, J., Plopper, C., Hyde, D.,St George, J., 1987. Regional differences in quantities of histochemically detectable mucosubstances in nasal, paranasal, and nasopharyngeal epithelium of the bonnet monkey. J. Histochem. Cytochem. 35, 279-286.

Harmsen, A., Kusser, K., Hartson, L., Tighe, M., Sunshine, M. J., Sedgwick, J. D., Choi, Y., Littman, D. R.,Randall, T. D., 2002. Cutting edge: organogenesis of nasalassociated lymphoid tissue (NALT) occurs independently of lymphotoxin- $\alpha$ (LT $\alpha)$ and retinoic acid receptor-related orphan receptor- $\gamma$, but the organization of NALT is LT $\alpha$ dependent. J. Immunol. 168, 986-990.

Henriksson, G., Helgeland, L., Midtvedt, T., Stierna, P.,Brandtzaeg, P., 2004. Immune response to Mycoplasma pulmonis in nasal mucosa is modulated by the normal microbiota. Am. J. Respir. Cell Mol. Biol. 31, 657-662.

Heritage, P., Underdown, B., Arsenault, A., Snider, D.,McDermott, M., 1997. Comparison of murine nasal-associated lymphoid tissue and Peyer's patches. Am. J. Respir. Crit. Care. Med. 156, 1256.

Hiroi, T., Iwatani, K., Iijima, H., Kodama, S., Yanagita, M.,Kiyono, H., 1998. Nasal immune system: distinctive Th0 and Th1/Th2 type environments in murine nasal-associated lymphoid tissues and nasal passage, respectively. Eur. J. Immunol. 28, 3346-3353.

Ichinohe, T., Pang, I. K., Kumamoto, Y., Peaper, D. R., Ho, J. H., Murray, T. S.,Iwasaki, A., 2011. Microbiota regulates immune defense against respiratory tract influenza A virus infection. Proc. Natl. Acad. Sci. U. S. A 108, 5354-5359.

Jeong, K., Suzuki, H., Nakayama, H.,Doi, K., 2000. Ultrastructural study on the follicleassociated epithelium of nasal-associated lymphoid tissue in specific pathogen-free (SPF) and conventional environment-adapted (SPF-CV) rats. J. Anat. 196, 443-451. 
Kang, H., Yan, M., Yu, Q.,Yang, Q., 2013. Characteristics of aasal-associated Lymphoid tissue (NALT) and nasal absorption capacity in chicken. PLoS ONE. 8, e84097.

Kang, H., Yan, M., Yu, Q.,Yang, Q., 2014. Characterization of Nasal cavity-associated lymphoid tissue in ducks. Anat. Rec. 297, 916-924.

Kelemen, G., 1947. The junction of the nasal cavity and the pharyngeal tube in the rat. Arch. Otolaryngol. 45, 159-168.

Kiyono, H.,Fukuyama, S., 2004. NALT-versusPeyer's-patch-mediated mucosal immunity. Nat. Rev. Immunol. 4, 699-710.

Koempel, J., Solares, C.,Koltai, P., 2006. The evolution of tonsil surgery and rethinking the surgical approach to obstructive sleep-disordered breathing in children. J. Laryngol. Otol. 120, 993-1000.

Koni, P. A., Sacca, R., Lawton, P., Browning, J. L., Ruddle, N. H.,Flavell, R. A., 1997. Distinct roles in lymphoid organogenesis for lymphotoxins $\alpha$ and $\beta$ revealed in lymphotoxin $\beta$-deficient mice. Immunity 6, 491-500.

Krege, J., Seth, S., Hardtke, S., Davalos-Misslitz, A. C. M.,Förster, R., 2009. Antigen-dependent rescue of nose-associated lymphoid tissue (NALT) development independent of LT $\beta R$ and CXCR5 signaling. Eur. J. Immunol. 39, 2765-2778.

Kuper, C. F., Koornstra, P. J., Hameleers, D. M., Biewenga, J., Spit, B. J., Duijvestijn, A. M., van Breda Vriesman, P. J.,Sminia, T., 1992. The role of nasopharyngeal lymphoid tissue. Immunol. Today 13, 219-224.

LaPatra, S., Kao, S., Erhardt, E. B.,Salinas, I., 2015. Evaluation of dual nasal delivery of infectious hematopoietic necrosis virus and enteric red mouth vaccines in rainbow trout (Oncorhynchus mykiss). Vaccine 33, 771-776.

Lee, H., Ruane, D., Law, K., Ho, Y., Garg, A., Rahman, A., Esterházy, D., Cheong, C., Goljo, E.,Sikora, A., 2015. Phenotype and function of nasal dendritic cells. Mucosal Immunol. 8, 1083-1098..

Liang, B., Hyland, L.,Hou, S., 2001. Nasal-associated lymphoid tissue is a site of longterm virus-specific antibody production following respiratory virus infection of mice. J. Virol. 75, 5416-5420.

Loo, S.,Chin, K., 1974. Lymphoid tissue in the nasal mucosa of primates, with particular reference to intraepithelial lymphocytes. J. Anat. 117, 249-259.

Lowrey, L., Woodhams, D. C., Tacchi, L.,Salinas, I., 2015. Topographical mapping of the rainbow trout (Oncorhynchus mykiss) microbiome reveals a diverse bacterial community in the skin with antifungal properties. Appl. Environ. Microbiol. 81, 6915-6925.

Lycke, N., 2012. Recent progress in mucosal vaccine development: potential and limitations. Nat. Rev. Immunol. 12, 592-605.

Mair, T., Batten, E., Stokes, C.,Bourne, F., 1987. The histological features of the immune system of the equine respiratory tract. J. Comp. Pathol. 97, 575-586.

Mair, T., Batten, E., Stokes, C.,Bourne, F., 1988. The distribution of mucosal lymphoid nodules in the equine respiratory tract. J. Comp. Pathol. 99, 159-168.

Mestecky, J., Lamm, M. E., Ogra, P. L., Strober, W., Bienenstock, J., McGhee, J. R.,Mayer, L., 2005. Mucosal Immunology. Academic Press, Amsterdam. 
Miyawaki, S., Nakamura, Y., Suzuka, H., Koba, M., Shibata, Y., Yasumizu, R.,Ikehara, S., 1994. A new mutation, aly, that induces a generalized lack of lymph nodes accompanied by immunodeficiency in mice. Eur. J. Immunol. 24, 429-434.

Myers, M. A., 1928. A study of the tonsillar developments in the lingual region of anurans. J. Morphol. 45, 399-439.

Neutra, M. R.,Kozlowski, P. A., 2006. Mucosal vaccines: the promise and the challenge. Nat. Rev. Immunol. 6, 148-158.

Ohshima, K.,Hiramatsu, K., 2000. Distribution of T-cell subsets and immunoglobulincontaining cells in nasal-associated lymphoid tissue (NALT) of chickens. Histol. Histopathol. 15, 713-720.

Pabst, R., 2015. Mucosal vaccination by the intranasal route. Nose-associated lymphoid tissue (NALT)-Structure, function and species differences. Vaccine 33, 4406-4413.

Peeters, D., Day, M., Farnir, F., Moore, P.,Clercx, C., 2005. Distribution of leucocyte subsets in the canine respiratory tract. J. Comp. Pathol. 132, 261-272.

Perry, M.,Whyte, A., 1998. Immunology of the tonsils. Immunol. Today 19, 414-421.

Plotkin, S., 2014. History of vaccination. Proc. Natl. Acad. Sci. U. S. A 111, 1228312287.

Randall, T.,Mebius, R., 2014. The development and function of mucosal lymphoid tissues: a balancing act with micro-organisms. Mucosal Immunol. 7, 455-466.

Rangel-Moreno, J., Moyron-Quiroz, J., Kusser, K., Hartson, L., Nakano, H.,Randall, T. D., 2005. Role of CXC chemokine ligand 13, CC chemokine ligand (CCL) 19, and CCL21 in the organization and function of nasal-associated lymphoid tissue. J. Immunol. 175, 4904-4913.

Rebelatto, M., Mead, C.,HogenEsch, H., 2000. Lymphocyte populations and adhesion molecule expression in bovine tonsils. Vet. Immunol. Immunopathol. 73, 1529.

Rodriguez-Monroy, M.,Moreno-Fierros, L., 2010. Striking activation of NALT and nasal passages lymphocytes induced by intranasal immunization with Cry1Ac protoxin. Scand. J. Immunol. 71, 159-168.

Rodríguez-Monroy, M. A., Rojas-Hernández, S.,Moreno-Fierros, L., 2007. Phenotypic and functional differences between lymphocytes from NALT and nasal passages of mice. Scand. J. Immunol. 65, 276-288.

Roland, P. S., Rosenfeld, R. M., Brooks, L. J., Friedman, N. R., Jones, J., Kim, T. W., Kuhar, S., Mitchell, R. B., Seidman, M. D.,Sheldon, S. H., 2011. Clinical practice guideline polysomnography for sleep-disordered breathing prior to tonsillectomy in children. OTO-HNS. 145, S1-S15.

Salinas, I., Zhang, Y.-A.,Sunyer, J. O., 2011. Mucosal immunoglobulins and B cells of teleost fish. Dev. Comp. Immunol. 35, 1346-1365.

Schuh, J.,Oliphant, L., 1992. Development and immunophenotyping of the pharyngeal tonsil (adenoid) in cattle. J. Comp. Pathol. 106, 229-241.

Shikina, T., Hiroi, T., Iwatani, K., Jang, M. H., Fukuyama, S., Tamura, M., Kubo, T., Ishikawa, H.,Kiyono, H., 2004. IgA class switch occurs in the organized nasopharynx-and gut-associated lymphoid tissue, but not in the diffuse lamina propria of airways and gut. J. Immunol. 172, 6259-6264. 
Smith, P. D., MacDonald, T. T.,Blumberg, R. S., 2013. Principles of mucosal immunology. Garland Science, New York.

Stanley, A., Huntley, J., Jeffrey, M.,Buxton, D., 2001. Characterization of ovine nasalassociated lymphoid tissue and identification of $\mathrm{M}$ cells in the overlying follicle-associated epithelium. J. Comp. Pathol. 125, 262-270.

Sun, Z., Unutmaz, D., Zou, Y.-R., Sunshine, M. J., Pierani, A., Brenner-Morton, S., Mebius, R. E.,Littman, D. R., 2000. Requirement for ROR $\gamma$ in thymocyte survival and lymphoid organ development. Science 288, 2369-2373.

Tacchi, L., Larragoite, Erin T., Muñoz, P., Amemiya, Chris T.,Salinas, I., 2015. African lungfish reveal the evolutionary origins of organized mucosal lymphoid tissue in vertebrates. Curr. Biol. 25, 1-8.

Tacchi, L., Musharrafieh, R., Larragoite, E. T., Crossey, K., Erhardt, E. B., Martin, S. A., LaPatra, S. E.,Salinas, I., 2014. Nasal immunity is an ancient arm of the mucosal immune system of vertebrates. Nat. Commun. 5, 6205.

Tamura, S.-i., Iwasaki, T., Thompson, A. H., Asanuma, H., Chen, Z., Suzuki, Y., Aizawa, C.,Kurata, T., 1998. Antibody-forming cells in the nasal-associated lymphoid tissue during primary influenza virus infection. J. Gen. Virol. 79, 291-299.

Weese, J. S., Slifierz, M., Jalali, M.,Friendship, R., 2014. Evaluation of the nasal microbiota in slaughter-age pigs and the impact on nasal methicillin-resistant Staphylococcus aureus (MRSA) carriage. BMC Vet. Res. 10, 69.

Xu, Z., Parra, D., Gómez, D., Salinas, I., Zhang, Y.-A., von Gersdorff Jørgensen, L., Heinecke, R. D., Buchmann, K., LaPatra, S.,Sunyer, J. O., 2013. Teleost skin, an ancient mucosal surface that elicits gut-like immune responses. Proc. Natl. Acad. Sci. U. S. A 110, 13097-13102.

Yan, M., Pamp, S. J., Fukuyama, J., Hwang, P. H., Cho, D.-Y., Holmes, S.,Relman, D. A., 2013. Nasal microenvironments and interspecific interactions influence nasal microbiota complexity and $S$. aureus carriage. Cell Host Microbe 14, 631-640.

Yokota, Y., Mansouri, A., Mori, S., Sugawara, S., Adachi, S., Nishikawa, S.-I.,Gruss, P., 1999. Development of peripheral lymphoid organs and natural killer cells depends on the helix-loop-helix inhibitor Id2. Nature 397, 702-706.

Younis, R. T.,Lazar, R. H., 2002. History and current practice of tonsillectomy. Laryngoscope 112, 3-5.

Zardoya, R.,Meyer, A., 1996. Evolutionary relationships of the coelacanth, lungfishes, and tetrapods based on the $28 \mathrm{~S}$ ribosomal RNA gene. Proc. Natl. Acad. Sci. U. S. A 93, 5449-5454.

Zhang, Y.-A., Salinas, I., Li, J., Parra, D., Bjork, S., Xu, Z., LaPatra, S. E., Bartholomew, J.,Sunyer, J. O., 2010. IgT, a primitive immunoglobulin class specialized in mucosal immunity. Nat. Immunol. 11, 827-835.

Zhang, Z., Bashiruddin, J., Doel, C., Horsington, J., Durand, S.,Alexandersen, S., 2006. Cytokine and Toll-like receptor mRNAs in the nasal-associated lymphoid tissues of cattle during foot-and-mouth disease virus infection. J. Comp. Pathol. 134, 56-62.

Zhao, X., Sato, A., Cruz, C. S. D., Linehan, M., Luegering, A., Kucharzik, T., Shirakawa, A.-K., Marquez, G., Farber, J. M.,Williams, I., 2003. CCL9 is secreted by the follicle-associated epithelium and recruits dome region Peyer's patch CD11b+ dendritic cells. J. Immunol. 171, 2797-2803. 
625 Zuercher, A. W., Coffin, S. E., Thurnheer, M. C., Fundova, P.,Cebra, J. J., 2002. Nasal626 associated lymphoid tissue is a mucosal inductive site for virus-specific humoral and cellular immune responses. J. Immunol. 168, 1796-1803.

628

629

630 Table 1

631 The differences between mice O-NALT and D-NALT.

\begin{tabular}{|c|c|c|c|}
\hline & O-NALT & D-NALT & References \\
\hline Number of lymphocytes & + & ++ & (Rodríguez-Monroy et al., 2007) \\
\hline \multirow[t]{2}{*}{$\mathrm{T} / \mathrm{B}$ cells ratio } & $0.76-1.2$ & $0.33-1.0$ & (Asanuma et al., 1997; \\
\hline & & & Rodríguez-Monroy et al., 2007) \\
\hline \multirow[t]{2}{*}{ Percentage of B cells ${ }^{1}$} & $47-79 \%$ & $55-74 \%$ & (Liang et al., 2001; \\
\hline & & & Rodríguez-Monroy et al., 2007) \\
\hline Plasma cells & + & ++ & (Rodríguez-Monroy et al., 2007) \\
\hline \multirow[t]{2}{*}{ IgM+ B cells } & 47 & $0.5-9 \%$ & (Rodríguez-Monroy et al., 2007; \\
\hline & $85 \%$ & & Shikina et al., 2004; Smith et al., \\
\hline IgA+ B cells & $1-1.6 \%$ & $7.7-10.8 \%$ & 2013) \\
\hline B220+hi B cells & Present & Present & (Rodríguez-Monroy et al., 2007) \\
\hline B220+hi B220+low B cells & Absent & Present & \\
\hline $\begin{array}{l}\text { IgM/IgG/IgA secreting cells } \\
\text { ratio (Uninfected) }\end{array}$ & $10 / 3 / 3$ & $10 / 3 / 3$ & (Asanuma et al., 1997) \\
\hline $\begin{array}{l}\text { IgM/IgG/IgA secreting cells } \\
\text { ratio (infected with influenza) }{ }^{2}\end{array}$ & $4 / 50 / 40$ & $1 / 25 / 10$ & \\
\hline IgM/IgG/IgA secreting cells & $1 / 80 / 125$ & $1 / 125 / 350$ & (Rodriguez-Monroy \\
\hline $\begin{array}{l}\text { ratio(immunized with Cry1Ac } \\
\text { protoxin) }\end{array}$ & & & Moreno-Fierros, 2010) \\
\hline
\end{tabular}

1.C57BL/6 mice have higher B cells percentage compared to BALB/c mice

2. 7 days post infection (dpi) with influenza

3 . BALB / c mice immunized intranasally 


\begin{tabular}{|c|c|c|c|}
\hline $\begin{array}{l}\text { IgM/IgG/IgA secreting cells } \\
\text { ratio(immunized with cholera } \\
\text { toxin) }\end{array}$ & $1 / 30 / 65$ & $1 / 90 / 160$ & \\
\hline IgA isotype class switching & Present & Absent & (Shikina et al., 2004) \\
\hline $\begin{array}{l}\text { Class switch recombination- } \\
\text { associated molecules }\end{array}$ & Present & Absent & \\
\hline $\begin{array}{l}\text { Long-lasting, specific effector } \\
\text { antibody response* }\end{array}$ & Absent & Present & (Liang et al., 2001) \\
\hline Frequency of AFCs* & + & ++ & (Liang et al., 2001) \\
\hline $\begin{array}{l}\text { Generation of virus-specific } \\
\text { antibody forming cells (AFCs)* }\end{array}$ & + & + & \\
\hline $\begin{array}{l}\text { Infected/uninfected } \quad \text { IFN- } \gamma \\
\text { production ratio }\end{array}$ & $\sim 1000$ & $\sim 700$ & (Asanuma et al., 1997) \\
\hline $\begin{array}{l}\text { Infected/uninfected } \\
\text { production ratio }\end{array}$ & 1 & 2 & \\
\hline $\mathrm{CD}^{+} \mathrm{T}$ cells & $30-40 \%$ & $13-20 \%$ & $\begin{array}{l}\text { (Rodríguez-Monroy et al., 2007; } \\
\text { Smith et al., 2013) }\end{array}$ \\
\hline $\mathrm{CD}^{+} / \mathrm{CD}^{+} \mathrm{T}$ cells ratio & $3-4.4$ & $1.5-6.4$ & $\begin{array}{l}\text { (Asanuma et al., 1997; Heritage et } \\
\text { al., 1997; Rodríguez-Monroy et al., } \\
\text { 2007; Smith et al., 2013) }\end{array}$ \\
\hline$\alpha \beta / \gamma \delta$ of $\mathrm{CD}^{+} \mathrm{T}$ cells ratio & $49-100$ & $2.5-3$ & (Heritage et al., 1997) \\
\hline $\begin{array}{l}\alpha \beta / \gamma \delta \text { of } \mathrm{CD}^{+} \mathrm{CD}^{-} \mathrm{T} \text { cells } \\
\text { ratio }\end{array}$ & $49-100$ & $49-100$ & \\
\hline $\begin{array}{l}\alpha \beta / \gamma \delta \text { of } \mathrm{CD}^{-} \mathrm{CD}^{+} \mathrm{T} \text { cells } \\
\text { ratio }\end{array}$ & $49-100$ & $9-19$ & \\
\hline $\begin{array}{l}\alpha \beta / \gamma \delta \text { of } \mathrm{CD}^{-} \mathrm{CD}^{-} \mathrm{T} \text { cells } \\
\text { ratio }\end{array}$ & $0-1$ & $0-1$ & \\
\hline Type of $\mathrm{CD} 4^{+} \mathrm{T}$ cells & $\mathrm{Th}_{0}$ & $\mathrm{Th}_{2}$ & $\begin{array}{l}\text { (Hiroi et al., 1998; Liang et al., } \\
\text { 2001) }\end{array}$ \\
\hline
\end{tabular}

4. 7 dpi with influenza 
632 Summary of major immune characteristics of mammalian organized and diffuse 633 NALT in mice: $++=$ high, $+=$ low. $\left({ }^{*}\right)$ showsresponses after influenza virus infection.

634

635

636

637

638

639

640

641

642

643

644

645

646

647

648

649

650

651

652 


\section{Table 2}

654 Requirements for the formation of NALT in mice.

\begin{tabular}{|c|c|c|}
\hline KO mice with & Organogenesis of NALT & References \\
\hline Id 2 & Absent & 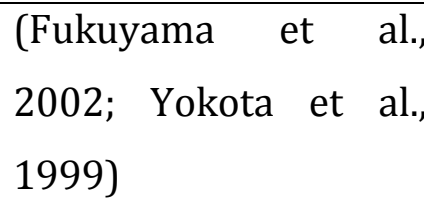 \\
\hline Ror- $\gamma \mathrm{t}$ & Not required/well developed & $\begin{array}{l}\text { (Harmsen et al., 2002; } \\
\text { Sun et al., 2000) }\end{array}$ \\
\hline Lt $\alpha$ & $\begin{array}{l}\text { Disorganized but developed } \\
\text { with fewer number of } \\
\text { lymphocytes }\end{array}$ & $\begin{array}{l}\text { (De Togni et al., 1994; } \\
\text { Fukuyama et al., 2002; } \\
\text { Harmsen et al., 2002) }\end{array}$ \\
\hline aly/aly & $\begin{array}{l}\text { Disorganized but developed } \\
\text { with fewer number of } \\
\text { lymphocytes }\end{array}$ & $\begin{array}{l}\text { (Fukuyama et al., } \\
\text { 2002; Miyawaki et al., } \\
\text { 1994) }\end{array}$ \\
\hline IL-7r $\alpha$ & $\begin{array}{l}\text { Disorganized but developed } \\
\text { with decreased number of } \\
\text { lymphocytes }\end{array}$ & $\begin{array}{l}\text { (Adachi et al., 1998; } \\
\text { Fukuyama et al., 2002; } \\
\text { Harmsen et al., 2002) }\end{array}$ \\
\hline $\mathrm{plt} / \mathrm{plt}$ & $\begin{array}{l}\text { Developed with decreased } \\
\text { number of lymphocytes }\end{array}$ & $\begin{array}{l}\text { (Fukuyama et al., } \\
\text { 2006; Rangel-Moreno } \\
\text { et al., 2005) }\end{array}$ \\
\hline Microbiota & Developed with delay & $\begin{array}{l}\text { (Randall and Mebius, } \\
\text { 2014) }\end{array}$ \\
\hline LT $\beta$ & Developed but disorganized & $\begin{array}{l}\text { (Fukuyama et al., } \\
\text { 2002; Koni et al., 1997) }\end{array}$ \\
\hline TRANCE & Developed but disorganized & $\begin{array}{l}\text { (Ache and Young, } \\
\text { 2005; Harmsen et al., } \\
\text { 2002) }\end{array}$ \\
\hline CXCL13/CCL19/CCL21 & Developed but disorganized & $\begin{array}{l}\text { (Ansel et al., 2000; } \\
\text { Fukuyama et al., 2006; }\end{array}$ \\
\hline
\end{tabular}




\section{Figure legends:}

659 Figure 1: Schematic diagram of the evolution of nasal immune systems in 660 vertebrates.

661 Figure 2: (A) Light micrograph (hematoxylin and eosin stain) of paraffin sections of 662 the olfactory organ of an Australian eel (Anguilaaustralis) showing the presence of 663 diffuse NALT in the form of scattered lymphocytes (black arrow heads). (B) Light 664 micrograph (hematoxylin and eosin stain) of the olfactory organ of the African 665 lungfish (Protopterusdolloi) showing the presence of a primordial lymphoid 666 aggregate (yellow arrows). NC: nasal cavity; OC: oral cavity; OE: olfactory 667 epithelium. Scale bar $=100 \mu \mathrm{m}$.

668 


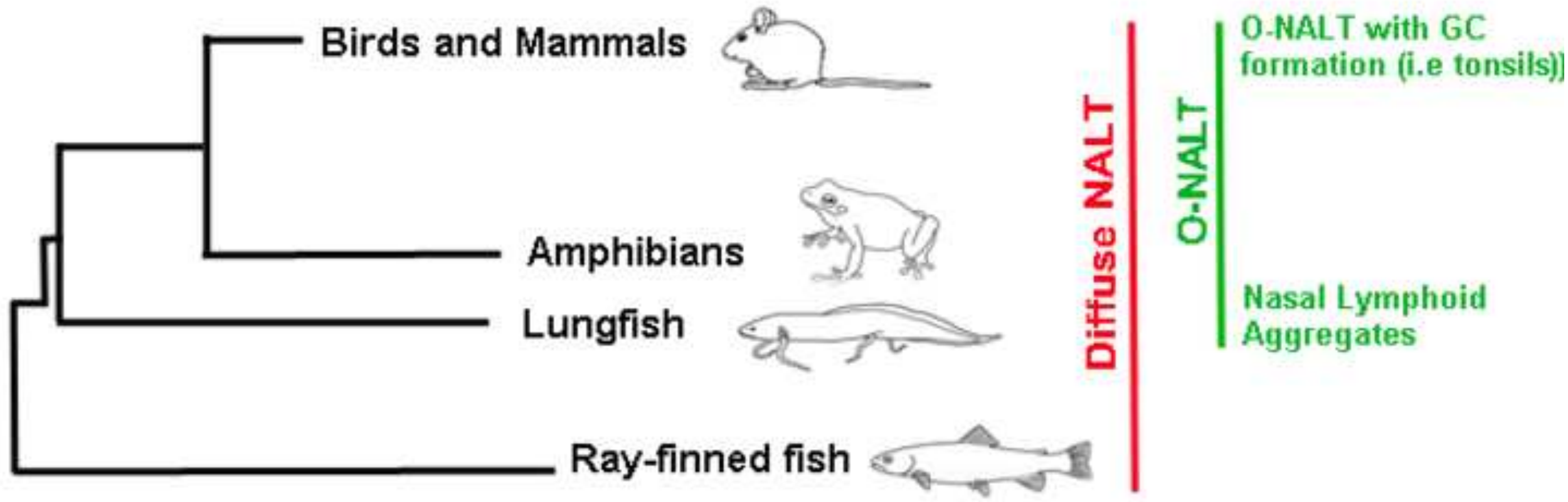




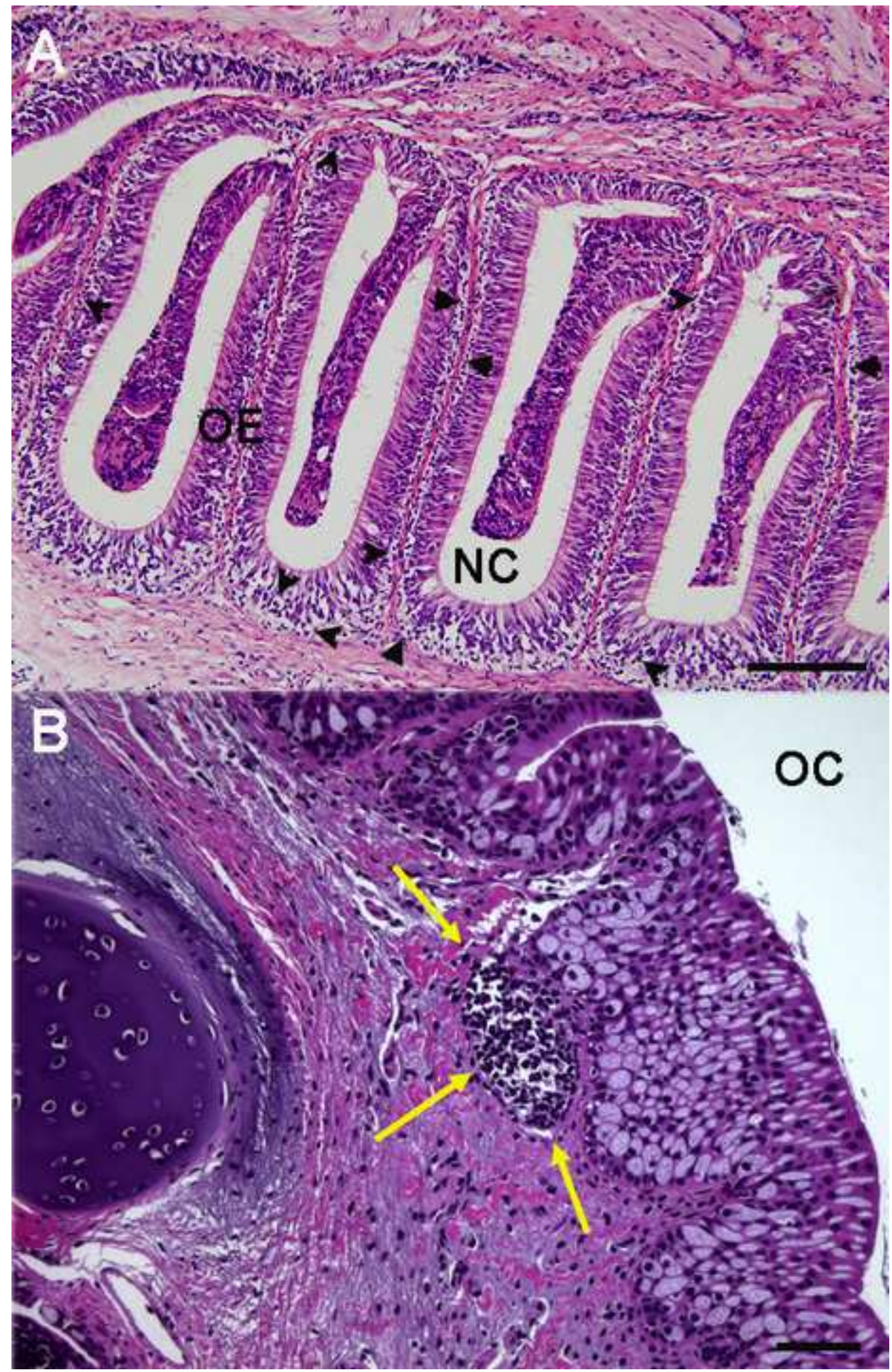

